\title{
Process Intensification by Using a Helical Capillary Microreactor for a Continuous Flow Synthesis of Peroxypropionic Acid and Its Kinetic Study
}

\author{
Yadagiri Maralla1, Shirish H. Sonawane ${ }^{1 *}$ \\ ${ }^{1}$ Department of Chemical Engineering, National Institute of Technology, Warangal, Telangana State - 506004, India \\ * Corresponding author, e-mail: shirish@nitw.ac.in
}

Received: 20 July 2018, Accepted: 21 September 2018, Published online: 28 January 2019

\begin{abstract}
Peroxypropionic acid (PPA) is an important organic chemical compound. Due to its versatile oxidizing properties, it is used in the oil, chemical and other industries. In this article, an attempt was made for the production of PPA in a Teflon helical capillary microreactor without and with homogeneous catalyst. The article reports the perhydrolysis of PPA with the effect of various parameters such as concentration of hydrogen peroxide, molar ratio of reactants, radius of curvature of the microreactor, concentration of catalyst and temperature. The reaction is slow, as the PPA equilibrium was found to be reached within $10 \mathrm{~min}$ at a temperature of $50^{\circ} \mathrm{C}$ and at $10 \mathrm{~mol} \%$ catalyst loading based on propionic acid. The reaction was carried out in 13.25 and $23.25 \mathrm{~mm}$ radius of curvature of the microreactor in which 4.0375 and $3.488 \mathrm{~mol} / \mathrm{L}$ concentrations of PPA respectively were obtained at $50^{\circ} \mathrm{C}$ and $10 \mathrm{~mol} \%$ catalyst. It indicates that as radius of curvature decreases, better mixing was provided among the reactants for the reaction to give enhanced yield and selectivity. From the experimental data and the kinetic expressions, the expressions of activation energies and reaction rate constants were determined. For PPA synthesis and hydrolysis, the activation energies were 43.897 and $20.658 \mathrm{~kJ} / \mathrm{mol}$ respectively without catalyst, while the activation energies for both the cases were 42.314 and $17.514 \mathrm{~kJ} / \mathrm{mol}$ respectively with catalyst of $10 \mathrm{~mol} \%$ based on propionic acid. The dean number, curve tube friction factor and pressure drop also determined for the helical capillary microreactor.
\end{abstract}

Keywords

peroxypropionic acid, capillary microreactor, homogeneous catalyst, hydrogen peroxide, kinetic study

\section{Introduction}

Peroxypropionic acid (perpropionic acid, PPA) is an organic compound with molecular formula of $\mathrm{C}_{2} \mathrm{H}_{5} \mathrm{COOOH}\left(\mathrm{RCOOOH}, \mathrm{R}=\mathrm{C}_{2} \mathrm{H}_{5}\right.$ ). It belongs to the family of peroxycarboxylic acids (PCA) [1-4]. The PCA are generally used due to its effective and high oxidative properties. The PCA are widely used for the destruction of pesticides, pollutants and as a bleaching agent in the paper industry and in the production of fine chemical substances [5-8]. The PPA is synthesized from the propionic acid (PA) and hydrogen peroxide (HP) as raw material and using sulfuric acid as a catalyst. It can also be synthesized without catalyst, but the conversion is low. So, in order to synthesize PPA, a catalyst is required, which may be a homogeneous catalyst such as mineral acids like sulfuric acid, phosphoric acid etc. $[6,9,10]$ or heterogeneous catalyst such as Amberlite IR-120, Amberlyst 15, Smopex-101,
Dowex etc. [8]. The chemical reaction is as shown in Scheme (I) [11]

$$
\mathrm{C}_{2} \mathrm{H}_{5} \mathrm{COOH}(\mathrm{A})+\mathrm{H}_{2} \mathrm{O}_{2}(\mathrm{~B}) \underset{\mathrm{k}_{2}}{\stackrel{\mathrm{k}_{1}}{\rightleftharpoons}} \mathrm{C}_{2} \mathrm{H}_{5} \mathrm{COOOH}(\mathrm{C})+\mathrm{H}_{2} \mathrm{O}(\mathrm{W}) \text {. }
$$

Currently, microreactor technology (MRT) is one of the best modern technologies in pharmaceutical, chemical production, process technology and chemical processing. From the last two decades, globally research accomplishments have impressively proved that microreactors whose internal geometry fall within the sub milliliter range. It provides numerous advantages in chemical process technology. Hence, a microreactor offers improved heat and mass transfer characteristics than batch reactors (conventional reactors) as a result of their high surface-to-volume ratio [12-14]. Consequently, the exothermic or hazardous reaction can safely carried out using the 
microreactors $[15,16]$. Better safety is managed, because of the small amount of hold-up within the microreactors. Besides better heat transfer, mass transfer, it also offers improved selectivity and yield. There is energy saving and improved safety over conventional batch production processes. This improvement is mainly significant in multiphase reaction systems like gas-liquid or liquid-liquid system and in other categories of mixing processes. Furthermore, MRT offers entry to new process methodologies and synthesis of various products. Currently, MRT has efficiently been employed as a tool for optimization and process screening in the research and development labs of chemical industries and research centers.

The helical capillary microreactor (HCMR) offers improved heat and mass transport as well as enhanced mixing among the reactants as compared to the planar microstructured reactors (PMR). The residence time distribution (RTD) is very narrow in the HCMR whereas the RTD is considerably broad in the PMR. It could be happen due to secondary flow formation by Dean Vortices in the HCMR [17]. Mixing taking place along the length of the microreactor in the PMR, whereas the mixing occurs along the length of the microreactor as well as in radial direction in the HCMR. So, the secondary flow in the HCMR, affects the rate of reaction and selectivity of the product in reduced residence time [17-20]. Therefore, in consequence of several advantages of the HCMR, an attempt was made to employ the HCMR for the synthesis of PPA.

So far there is no report on the synthesis of peroxypropionic acid in a microreactor. So that, to study the capillary microreactor performance and reaction behavior, the synthesis of peroxypropionic acid reaction was selected. This article reports, the usage of HCMR for the safe processing of PPA reaction in the liquid-liquid regime. Detailed kinetic study and the effect of curvature on peroxypropionic acid reaction were also reported.

\section{Experimental methods}

\subsection{Materials and chemicals}

Propionic acid (PA, $\mathrm{C}_{2} \mathrm{H}_{5} \mathrm{COOH}, 99.5 \%$ ) and ammonium cerium sulphate $\left(\mathrm{ACS},\left(\mathrm{NH}_{4}\right)_{4} \mathrm{Ce}\left(\mathrm{SO}_{4}\right)_{4} \cdot 2 \mathrm{H}_{2} \mathrm{O}, 98 \%\right.$ ) were obtained from Sisco Research Laboratories Pvt. Ltd., Mumbai, India. Hydrogen peroxide ( $\left.\mathrm{HP}, \mathrm{H}_{2} \mathrm{O}_{2}, 30 \% \mathrm{w} / \mathrm{w}\right)$ and sulfuric acid (SA, $\mathrm{H}_{2} \mathrm{SO}_{4}, 97 \%$ ) were obtained from Fisher Scientific, Mumbai, India. Potassium iodide (KI), ferroin solution (as an indicator) and sodium thiosulphate (STS, $\mathrm{Na}_{2} \mathrm{~S}_{2} \mathrm{O}_{3} \cdot 5 \mathrm{H}_{2} \mathrm{O}$ ) were procured from $\mathrm{S}$ D Fine-chem Limited, Mumbai, India. Starch maize powder (SMP, corn, $\left.\left(\mathrm{C}_{6} \mathrm{H}_{10} \mathrm{O}_{5}\right)_{\mathrm{n}}\right)$ was obtained from Molychem, Mumbai, India. PA and HP were reactants and SA employed as a catalyst. ACS, FI (indicator), STS, KI and SMP Solutions (indicator) were employed for the analysis of peroxypropionic acid product. The required stock solutions were prepared using distilled water. The rate of formation of PPA was studied. The PPA synthesis reaction is presented in Scheme (I). The reaction was accomplished in the absence and presence of a homogeneous catalyst (sulfuric acid).

\subsection{Procedure for the synthesis of PPA and experimental setup}

All experiments were carried out in Teflon helical capillary microreactor (THCMR). The graphical representation of the experimental system for the synthesis of PPA has been shown in Fig. 1. The experimental system contains of THCMR, syringes, syringe pumps and water bath to maintain the temperature of the reaction. The volume of THCMR is $1.0 \mathrm{~mL}(I D=0.80, O D=1.0 \mathrm{~mm}$, radius of curvature $=13.25 \mathrm{~mm} / 23.25 \mathrm{~mm}$ and Length $=2 \mathrm{~m}$ ). In order to perform the experiments, syringe pumps were employed to feed the raw materials into the THCMR. The feed flow rates were kept at 5 to $72 \mathrm{~mL} / \mathrm{h}$ for the experiments with catalyst (or $1.33-12.0 \mathrm{~mL} / \mathrm{h}$ for the experiments without catalyst). The reactants PA (without and with catalyst) and HP were allowed into the microreactor by employing syringe pumps. The reactants were added at different molar ratios. The experiments were conducted without and with a homogeneous catalyst of sulfuric acid at similar operating environments. It was observed that the presence of a catalyst in a reaction mixture increases the rate of reaction and increases yield in shorter time as compared to reaction carried out without catalyst. The experiments were performed

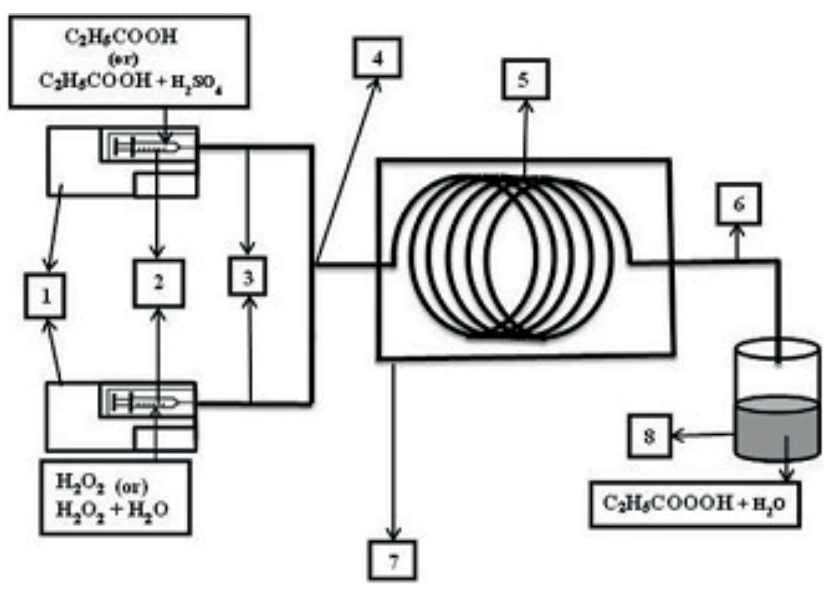

Fig. 1 The graphical representation of experimental system for the synthesis of PPA 
by changing parameters like concentration of HP, molar ratio of reactants, radius of curvature of the microreactor and temperature to establish the best operating conditions for the PPA synthesis in THCMR. The experimental runs were carried out at different temperatures (30, 40, 50 and $60{ }^{\circ} \mathrm{C}$ ) by maintaining constant water bath temperature. The highest operating temperature was kept at $60{ }^{\circ} \mathrm{C}$ as above $60{ }^{\circ} \mathrm{C}$ the PPA generates vapors. The product samples were collected from THCMR and analyzed immediately. The experimental parameters have been shown in Table 1. The analysis method is given in Section 2.3.

1. Syringe pumps (Model: Caddo 15B),

2. Plastic syringes,

3. Inlets,

4. T-Mixer $(I D=0.8 \mathrm{~mm})$,

5. Teflon helical capillary microstructured reactor (THCMR) for reaction $(I D=0.80 \mathrm{~mm}, O D=1.5 \mathrm{~mm}$, radius of curvature $=13.25 \mathrm{~mm} / 23.25 \mathrm{~mm}$ and Length $=2 \mathrm{~m})$,

6. Outlet,

7. Water bath to maintain the temperature of the system and

8. Glass beaker for collecting the product.

\subsection{Analysis method}

The liquid phase of the sample (product) was analyzed off - line by titration procedures of Greenspan and Mackellar method [6, 8, 10, 21-23]. The concentration of HP was determined by titration against a prepared standard solution of ACS and the concentration of PPA was determined by titration against a prepared standard solution of sodium thiosulphate. The titer values were recorded and the percentage conversions of PA as well as concentration of PPA were estimated.

\section{Results and Discussion}

\subsection{Effect of hydrogen peroxide concentration on PPA synthesis}

In a chemical process, the selection of concentration of raw materials is one of the most important parameters, which plays a vital role in the conversion of reactants into desired products. As the concentration of one of the reactant increases, it shows the effect in the conversion of the other reactant and which alters reaction time as well as the yield of the product and selectivity. So, in this section, three different concentrations of HP for example 20, 25 and $30 \% \mathrm{w} / \mathrm{w}$ were studied for the synthesis of PPA at $50{ }^{\circ} \mathrm{C}$ and $10 \mathrm{~mol} \%$ catalyst based on the propionic acid.
Table 1 List of parameters and their range in the experiments

\begin{tabular}{ll}
\hline Parameter & Range \\
\hline HP Assay & 20,25 and $30 \% \mathrm{w} / \mathrm{w}$ \\
Molar ratio ( HP to PA) & $1: 0.75,1: 1$ and $1: 1.25$ \\
Catalyst loading (based on the PA & $4,6,8,10$ and 12 \\
mole \%) & \\
Temperature & $30,40,50$ and $60{ }^{\circ} \mathrm{C}$ \\
HP concentration & $4.33-6.10 \mathrm{~mol} / \mathrm{L}$ \\
PA concentration & $4.33-6.51 \mathrm{~mol} / \mathrm{L}$ \\
\hline
\end{tabular}

The HP of concentration $30 \% \mathrm{w} / \mathrm{w}$ is used as received, while 20 and $25 \% \mathrm{w} / \mathrm{w}$ concentration of HP were prepared in the laboratory by adding double distilled water. From Fig. 2, it was confirmed that the HP concentration of $30 \% \mathrm{w} / \mathrm{w}$ shows a high conversion of PA as compared to 20 and $25 \%$ w/w HP. From the Fig. 2, it is observed that maximum PPA concentration is recorded at highest concentration of HP (i.e., $30 \% \mathrm{w} / \mathrm{w}$ ). Thus, from Fig. 2, it could be concluded that $30 \% \mathrm{w} / \mathrm{w}$ HP is preferable for the synthesis of PPA for better selectivity, yield and quality. Furthermore, it could be inferred that $30 \% \mathrm{w} / \mathrm{v}$ HP and 10 mol \% catalyst at $50{ }^{\circ} \mathrm{C}$ affords high conversion of PA $\left(X_{A}=72.36 \%\right)$ within $10 \mathrm{~min}$ residence time [10, 23, 24].

\subsection{Molar ratio of hydrogen peroxide and propionic acid}

Fig. 3 describes the effect of HP to PA molar ratio from 1: 0.75 to $1: 1.25[25,26]$ for the synthesis of PPA at $50{ }^{\circ} \mathrm{C}$ and $10 \mathrm{~mol} \%$ catalyst loading based on PA at a total flow rate from 5 to $72 \mathrm{~mL} / \mathrm{h}$ (residence time of $12 \mathrm{~min}$ to $50 \mathrm{~s}$ ). Generally, for any tubular reactor / plug flow reactor, the residence time is the ratio of volume of the reactor to the volumetric flow rate to the reactor. That is $\tau=V / v$, where $V$

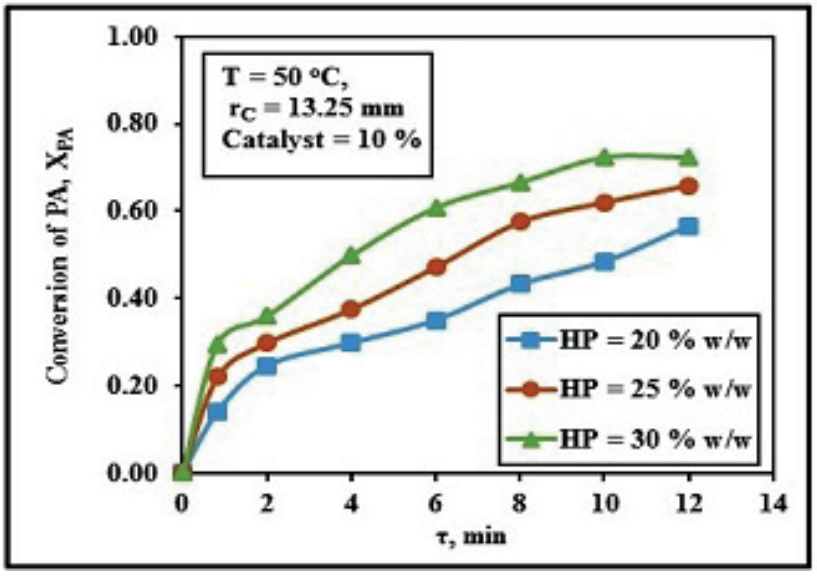

Fig. 2 Effect of hydrogen peroxide concentration on the conversion of propionic acid 


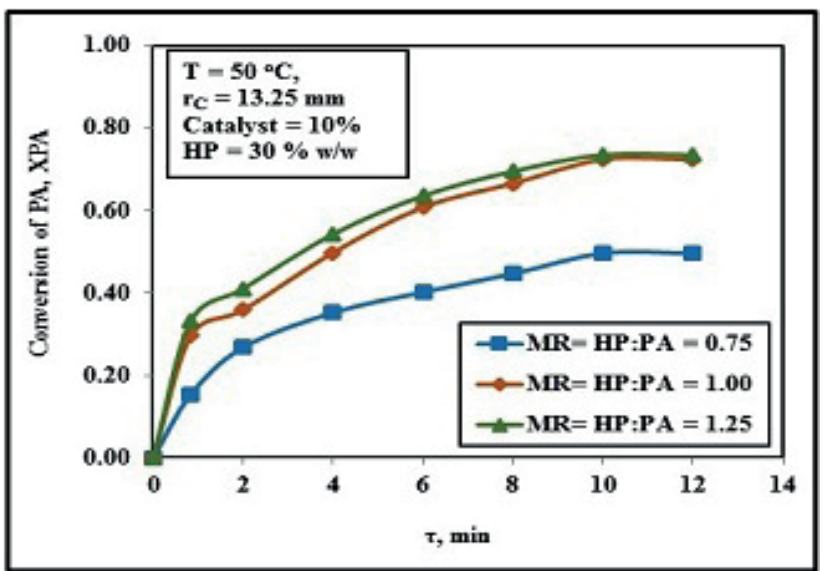

Fig. 3 Effect of molar ratio of propionic acid to hydrogen peroxide for the synthesis of PPA

is volume of the capillary microreactor and $v$ is the volumetric flow rate to the capillary microreactor. According to the reaction scheme $(I)$ stated, the aforementioned has been observed that 1 mole of PA reacts with 1 mole HP to afford 1 mole of PPA. From Fig. 3, it has been observed that the conversion of PA enhances from 49.62 to $73.46 \%$ with an increase in the molar ratio of HP to PA from 1: 0.75 to $1: 1.25$ respectively. Further, when compared to molar ratio of HP to PA of $1: 1$ and 1: 1.25, it was noticed that by increasing beyond the molar ratio of $1: 1.25$, there is no significant effect of the molar ratio on the synthesis of PPA. Furthermore, when compared to the molar ratio of HP to PA of 1:1 and 1: 1.25 gave almost same conversion of PA. Thus, from Fig. 3, it could be concluded that the molar ratio of 1:1 of HP to PA is preferred for the synthesis of PPA. Nevertheless, using excess HP does not lead to higher conversion.

Microstructured reactor with very large surface area for a chemical reaction [27-30] which enhances the reaction rate for the formation of PPA and offers less time in capillary microreactor. Moreover, the concentration of PPA was observed to be constant, it was reduced after a residence time of $10 \mathrm{~min}$. This is because of the backward hydrolysis reaction between PPA and water which takes place to form PA and HP due to the decomposition of PPA or PPA decomposes into $\mathrm{CO}_{2}$ and water.

\subsection{Effect of radius of curvature of the helical capillary microstructured reactor}

Helical capillary microstructured reactor with bends/ turns have been planned for continuous flow applications as it provides well residence time distributions (RTD), enhanced heat as well as mass transfer in laminar stream/regimes for the residence times up to few minutes/ seconds based on the reaction type [27-34]. As the diameter of a microreactor increases, it decreases the bombardment among the particles, which leads to ineffective mixing and increase in diffusion path length. This will slow down reaction rate. While the diameter of a microreactor decreases it leads to increase the bombardment among the particles, which enhances the mixing of the reactants. This will decreases diffusion path length which leads increase in reaction rate and finally it attain the equilibrium in small time for reversible reactions [34].

Further, continuous flow synthesis of performic acid from formic acid and HP in the presence of sulfuric acid as a homogeneous catalyst in spiral capillary microreactor was reported by Yadagiri Maralla and Shirish Sonawane (2018). However, the comparison of two different radius of curvature was used to study the behavior of THCMR for the synthesis of PPA was reported [10].

In this article, two different radius of curvatures were applied to study the performance of THCMR for the synthesis of PPA at $50{ }^{\circ} \mathrm{C}$ and at $10 \mathrm{~mol} \%$ catalyst loading based on PA at various total feed flow rates. Here, the radius of curvatures employed were $23.25 \mathrm{~mm}$ and $13.25 \mathrm{~mm}$ having number of turns of 12 and 21 respectively. However, when the radius of curvature reduces, the number of turns increases which results into enhanced mixing, improved mass and heat transfer, vice versa. A lesser radius of curvature of THCMR leads to give in higher conversion of PA. From Fig. 4, it was found that at $50{ }^{\circ} \mathrm{C}$ and at $10 \mathrm{~mol} \%$ catalyst loading based on $\mathrm{PA}$, radius of curvatures of $13.25 \mathrm{~mm}$ of THCMR, gave maximum conversion of PA, $X_{P A}=72.36 \%$, whereas $23.25 \mathrm{~mm}$ THCMR gave maximum conversion of PA, $X_{P A}=62.52 \%$. Furthermore, it would be concluded that $13.25 \mathrm{~mm}$ THCMR is the best continuous flow capillary microreactor for the synthesis of PPA.

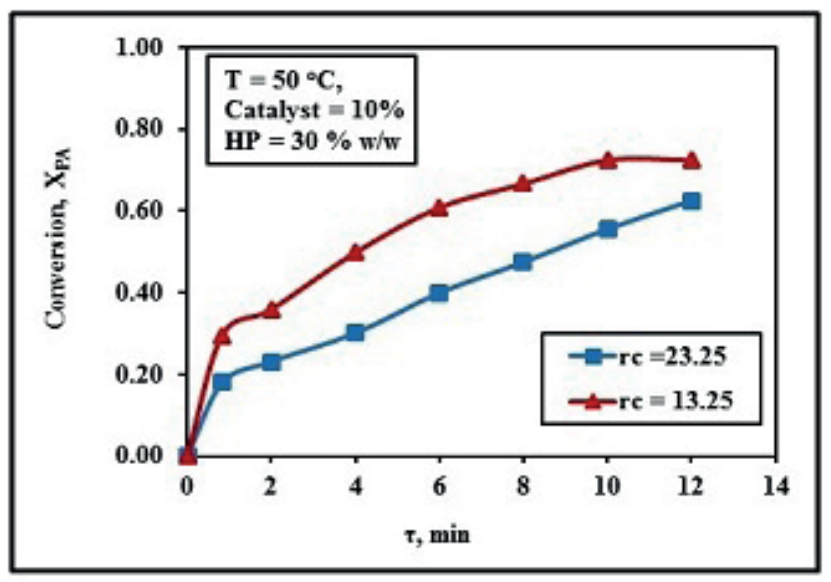

Fig. 4 Effect of radius of curvature on the synthesis of PPA 


\subsection{Effect of catalyst loading on the synthesis of PPA}

Fig. 5 describes the effect of catalyst concentration on the PPA formation by maintaining constant molar ratio of HP to PA at $1: 1$ and at $50{ }^{\circ} \mathrm{C}[26,35-38]$. The conversion of PA at $4 \mathrm{~mol} \%$ of catalyst loading was observed to be $X_{P A}=60.20 \%$. The conversion of PA was observed to be increased from 60.20 to $73.51 \%$ at the catalyst loading from 4 to $12 \mathrm{~mol} \%$ at $50{ }^{\circ} \mathrm{C}$. This is due to the presence of higher number of $\mathrm{H}^{+}$ions at high catalyst concentration. As the sulfuric acid concentration increases which leads to provide more active $\mathrm{H}^{+}$ions, it enhances the rate of reaction to obtain the equilibrium of the reaction in lesser time and also increases the yield as well as the selectivity of the products. On the other hand, higher concentration of catalyst i.e. above $12 \mathrm{~mol} \%$ at $50{ }^{\circ} \mathrm{C}$, the conversion of PA was observed to be closer to $X_{P A}=73.51 \%$, which is almost near to $10 \mathrm{~mol} \%$ of catalyst concentration. It is due to the adequate numbers of $\mathrm{H}^{+}$ions being delivered by the catalyst concentration of $10 \mathrm{~mol} \%$. Furthermore, even though a larger number of $\mathrm{H}^{+}$ions were prevailing at a catalyst concentration of $12 \mathrm{~mol} \%$, the presence of insufficient quantities of PA confines the PPA formation in the THCMR. Therefore, the conversion of PA remains unaltered. In the present work, the equilibrium is reached at the end of $10 \mathrm{~min}$. Hence, from Fig. 5, it could be concluded that $10 \mathrm{~mol} \%$ catalyst concentrations is the best one at $50{ }^{\circ} \mathrm{C}$ and $30 \% \mathrm{w} / \mathrm{w}$ HP to produce PPA by using the THCMR with a radius of curvature of $13.25 \mathrm{~mm}$.

\subsection{Effect of temperature on the synthesis of PPA}

Experiments were performed at various temperatures in the range of 30 to $60^{\circ} \mathrm{C}$ to study the temperature effect on the synthesis of PPA. The effect of the temperature for the

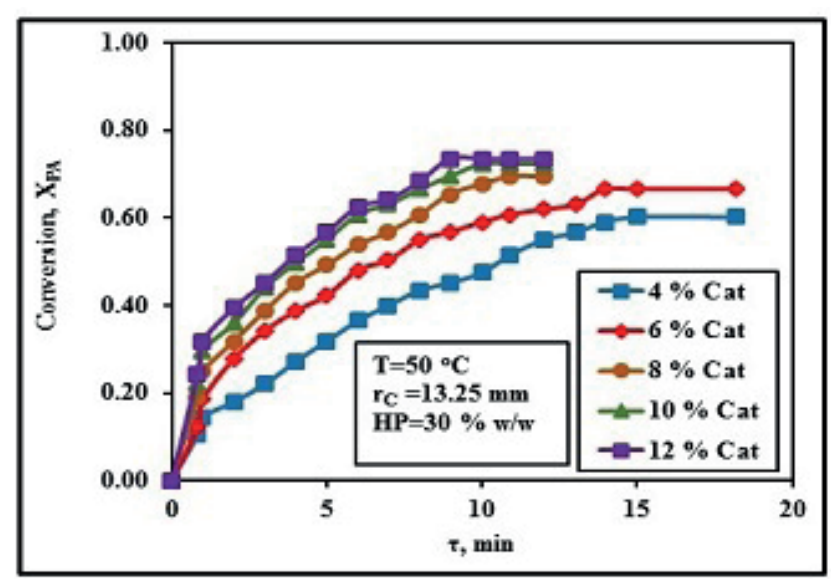

Fig. 5 Effect of catalyst concentration on the synthesis of PPA synthesis of PPA has been represented in Fig. 6 (a) and (b) without and with catalyst of $10 \mathrm{~mol} \%$ based on PA respectively. The total feed flow rate of reactants were kept in the range of $1.33-12 \mathrm{ml} / \mathrm{h}$ and $5-72 \mathrm{~mL} / \mathrm{h}$, molar ratio of HP to PA is $1: 1$ and catalyst loading of 0 and $10 \mathrm{~mol} \%$ based on PA in the temperature range of 30 to $60{ }^{\circ} \mathrm{C}$ respectively. The concentration of PPA was found to be $0.4522 \mathrm{~mol} / \mathrm{L}\left(X_{P A}=8.10 \%\right)$ at a residence time of $45 \mathrm{~min}$ at $30{ }^{\circ} \mathrm{C}$ and was noticed to be increased to $0.6460 \mathrm{~mol} / \mathrm{L}$ $\left(X_{P A}=11.58 \%\right)$ at a residence time of $45 \mathrm{~min}$ at $60^{\circ} \mathrm{C}$ in the absence of a catalyst. Similarly, the concentration of PPA was found to be $3.4884 \mathrm{~mol} / \mathrm{L}\left(X_{P A}=62.52 \%\right)$ at a residence time of $12 \mathrm{~min}$ at $30{ }^{\circ} \mathrm{C}$ and was noticed to be enhanced to $4.0375 \mathrm{~mol} / \mathrm{L}\left(X_{P A}=72.36 \%\right)$ at a residence time of $10 \mathrm{~min}$ at $50{ }^{\circ} \mathrm{C}$ in the presence of homogeneous catalyst loading at $10 \mathrm{~mol} \%$ based on PA. It was observed that as the temperature increases the rate of reaction increases which results in an increase in the reactants conversion and further which leads to obtain better product with improved yield and selectivity. Then, it was observed that reduction in the formation of peroxypropionic acid at
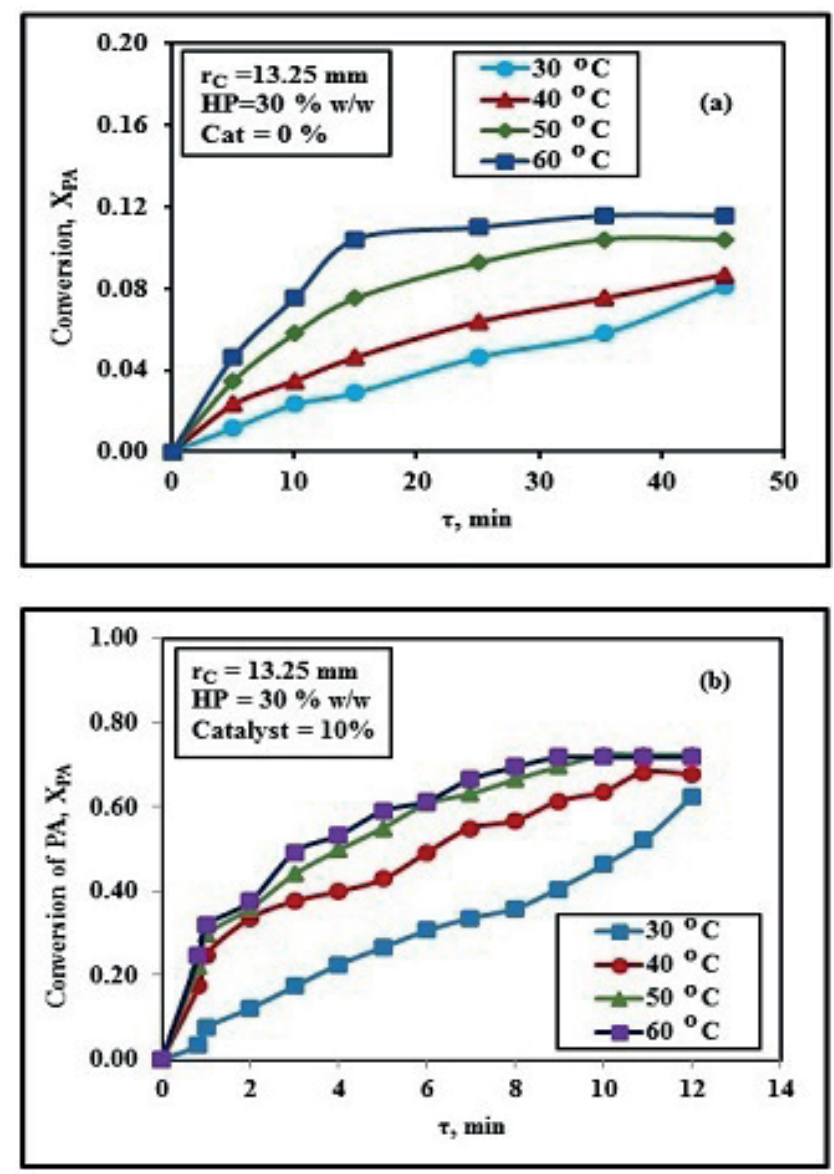

Fig. 6 Effect of temperature on the synthesis of PPA (a) without catalyst (b) with catalyst 
temperatures above $60^{\circ} \mathrm{C}$ due to the decomposition of the peroxypropionic acid [2].

This is because of the decomposition of PPA at higher temperature (above $80^{\circ} \mathrm{C}$ ) and higher catalyst concentration causes the reduction in the concentration of PPA at $60{ }^{\circ} \mathrm{C}$ compared to $50{ }^{\circ} \mathrm{C}$. In addition, at higher temperature and high concentration of catalyst, vapors of reaction mixture gets formed in the microreactor ensuing in less effective reactivity among the reactants, which consequences in the lower conversion of PA and thus decreases the reaction rate. On the contrary, at lower temperature $\left(50^{\circ} \mathrm{C}\right)$, the vapor pressure of the reaction mixture is low. Consequently, the small amount of vapor exists in the microreactor leads to more reactivity among the reactants which results into the reaction leading to more formation of PPA and that enhances the reaction rate at $50{ }^{\circ} \mathrm{C}$. Hence, the optimum temperature was found to be $50{ }^{\circ} \mathrm{C}$.

\subsection{Formation of kinetic model and finding of kinetics constants}

\subsubsection{Suppositions of a kinetic model}

Before developing the kinetic model, following assumptions were made.

- The reaction volume is constant during the reaction at a temperature.

- HP is unchanged when no catalyst was used in the reaction, even at higher temperature up to some extent. Furthermore, thermal decomposition of PPA is apparent merely at temperature above $80^{\circ} \mathrm{C}$ [1-4].

- Further, there is assured quantity of water would be produced in the synthesis of PPA and it is a robust group of nucleophilic than HP and PPA. Hence, the depletion of PPA is mostly owing to that its hydrolysis.

Hence, the reaction Scheme (I) consist of the two main reactions, synthesis of PPA and hydrolysis of PPA

$$
\mathrm{C}_{2} \mathrm{H}_{5} \mathrm{COOH}(\mathrm{A})+\mathrm{H}_{2} \mathrm{O}_{2}(\mathrm{~B}) \underset{\mathrm{k}_{2}}{\stackrel{\mathrm{k}_{1}}{\rightleftharpoons}} \mathrm{C}_{2} \mathrm{H}_{5} \mathrm{COOOH}(\mathrm{C})+\mathrm{H}_{2} \mathrm{O}(\mathrm{W}) \text {. }
$$

\subsubsection{Determination of kinetic constants}

The PPA synthesis and hydrolysis without and with homogeneous catalyst were used to estimate the reaction rate constants. Fig. 7 and Fig. 9 show the residence time effect on the synthesis of PPA without and with catalyst respectively at different temperatures. The data stated in Fig. 8 and Fig. 10 was used to find the activation energies and the reaction rate constants of the Scheme (I) without and with

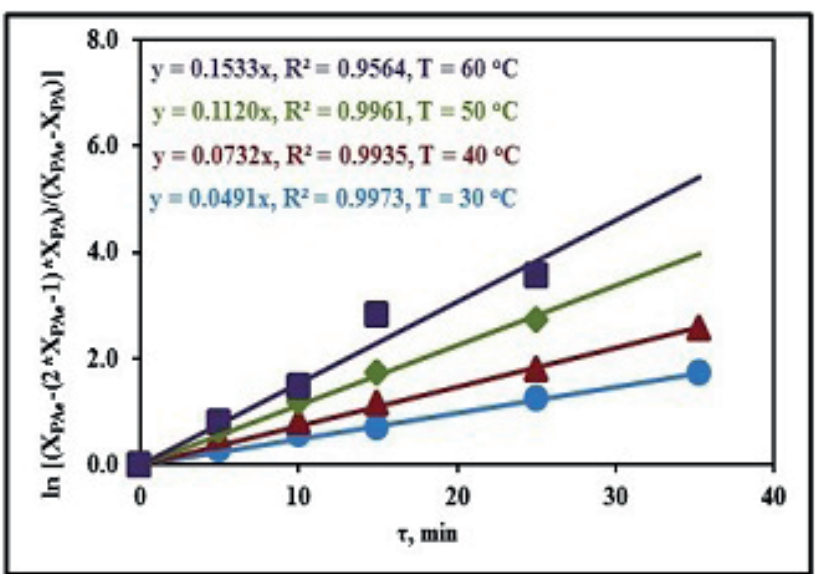

Fig. 7 The plot of residence time Vs $\ln$ (conversion) for the synthesis of PPA to determine the rate constants at different temperatures without catalyst

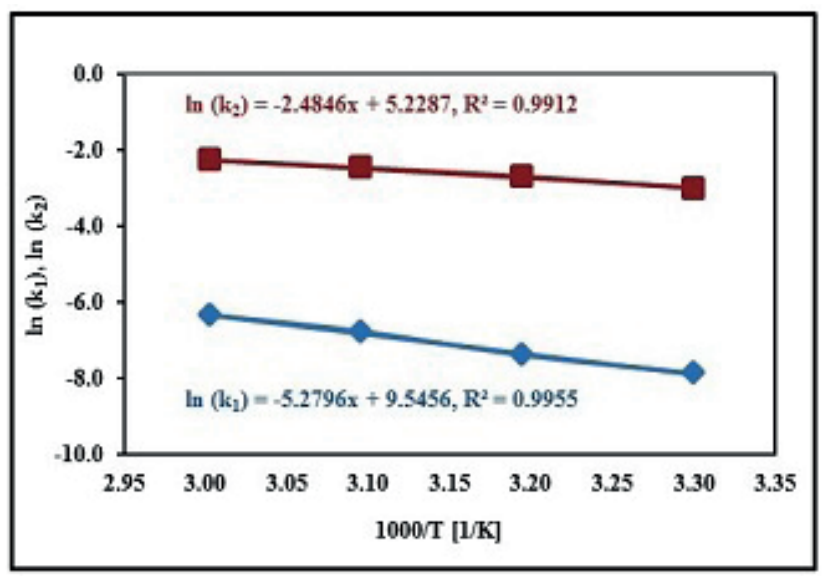

Fig. 8 Arrhenius plots for the synthesis of PPA without catalyst

catalyst respectively. A very few researchers have stated that at higher temperatures (i.e. $>80^{\circ} \mathrm{C}$ ) [2], PCA decomposes into $\mathrm{O}_{2}, \mathrm{H}_{2} \mathrm{O}$ and $\mathrm{CO}_{2}[10,38]$. A very few researchers stated the kinetic model for the synthesis of PPA and decomposition of PPA in a conventional batch method [6, 8]. In this study, a kinetic model was established for the synthesis of PPA without and with catalyst by treating THCMR as a model of plug flow reactor (PFR).

The kinetic model for the Scheme (I) of PPA could be described by Eqs. (1)-(4)

$$
\begin{aligned}
-r_{P A} & =-r_{H P}=-\frac{d C_{P A}}{d t}=-\frac{d C_{H P}}{d t}=\left(k_{1} C_{P A} C_{H P}-k_{2} C_{P P A} C_{W}\right) \\
r_{P P A} & =r_{W}=\frac{d C_{P P A}}{d t}=\frac{d C_{W}}{d t}=\left(k_{1} C_{P A} C_{H P}-k_{2} C_{P P A} C_{W}\right) \\
-r_{P A} & =-r_{H P}=-\frac{d C_{P A}}{d t}=-\frac{d C_{H P}}{d t} \\
& =\left(k_{1} C_{P A} C_{H P}-k_{2} C_{P P A} C_{W}\right) C_{S A}
\end{aligned}
$$




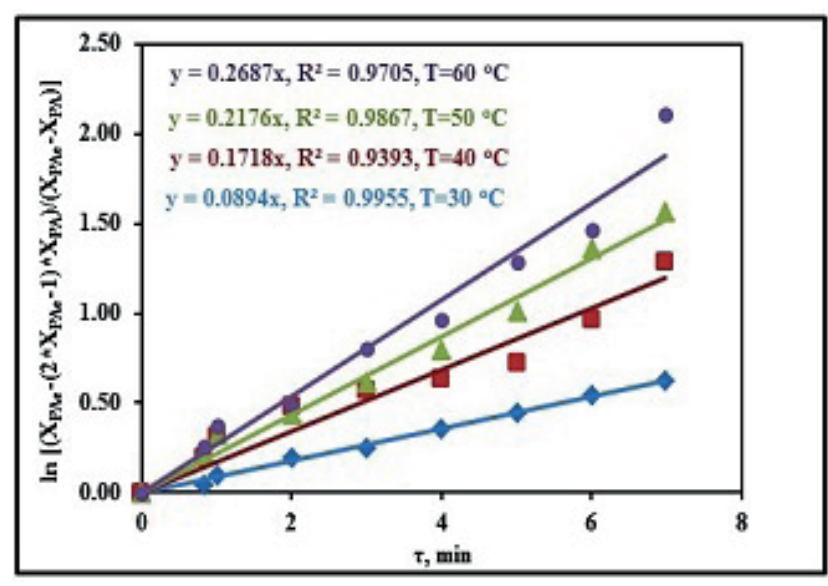

Fig. 9 The plot of residence time Vs $\ln$ (conversion) for the synthesis of PPA to determine the rate constants at different temperatures with catalyst (10 mol \%)

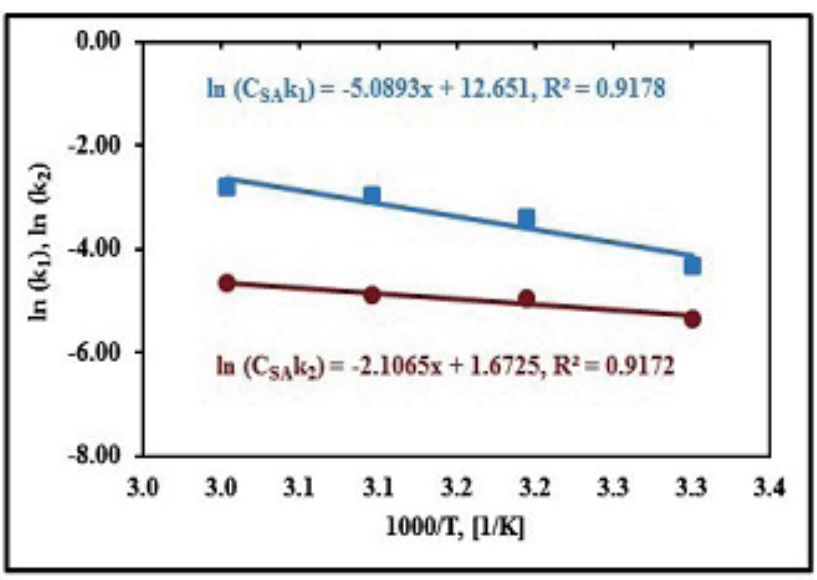

Fig. 10 Arrhenius plots for the synthesis of PPA with catalyst (10 mol \%)

$r_{P P A}=r_{W}=\frac{d C_{P P A}}{d t}=\frac{d C_{W}}{d t}=\left(k_{1} C_{P A} C_{H P}-k_{2} C_{P P A} C_{W}\right) C_{S A}$.

Eq. (1) and Eq. (2) represent the kinetic model for the reaction of without catalyst and Eq. (3) and Eq. (4) represents the kinetic model for the reaction of with catalyst.

After the components balance, the PA concentration and water concentration were by Eqs. (5)-(7)

$$
\begin{aligned}
& C_{P A}=C_{P A 0}-\left(C_{H P 0}-C_{H P}\right) \\
& C_{P A}=C_{P A 0}-C_{P P A} \\
& C_{W}=C_{W 0}+\left(C_{H P 0}-C_{H P}\right) .
\end{aligned}
$$

Where $C_{Z 0}$ is the concentration at time $t=0$ and $C_{Z}$ is the concentration at time $t$ of species $Z$. Therefore, the kinetic models could be written by Eqs. (8)-(11)

$$
\begin{aligned}
-r_{P A} & =-r_{H P}=-\frac{d C_{P A}}{d t}=-\frac{d C_{H P}}{d t} \\
& =\left(k_{1}\left(C_{P A 0}-C_{P P A}\right) C_{H P}-k_{2} C_{P P A}\left(C_{W 0}+\left(C_{H P 0}-C_{H P}\right)\right)\right) \\
r_{P P A} & =r_{W}=\frac{d C_{P P A}}{d t}=\frac{d C_{W}}{d t} \\
& =\left(k_{1}\left(C_{P A 0}-C_{P P A}\right) C_{H P}-k_{2} C_{P P A}\left(C_{W 0}+\left(C_{H P 0}-C_{H P}\right)\right)\right) \\
-r_{P A} & =-r_{H P}=-\frac{d C_{P A}}{d t}=-\frac{d C_{H P}}{d t} \\
& =\left(\begin{array}{l}
k_{1}\left(C_{P A 0}-C_{P P A}\right) C_{H P} \\
-k_{2} C_{P P A}\left(C_{W 0}+\left(C_{H P 0}-C_{H P}\right)\right)
\end{array}\right) C_{S A} \\
r_{P P A} & =r_{W}=\frac{d C_{P P A}}{d t}=\frac{d C_{W}}{d t} \\
& =\left(\begin{array}{l}
k_{1}\left(C_{P A 0}-C_{P P A}\right) C_{H P} \\
-k_{2} C_{P P A}\left(C_{W 0}+\left(C_{H P 0}-C_{H P}\right)\right)
\end{array}\right) C_{S A}
\end{aligned}
$$

For a PFR model (by assuming), the performance equation is by Eqs. (12)-(14)

Input $=$ output + disappearance by the reaction

$F_{P A}=\left(F_{P A}+d F_{P A}\right)+\left(-r_{P A}\right) d V$

$F_{P A 0} d X_{P A}=\left(-r_{P A}\right) d V$.

Eq. (12) to Eq. (14) represents the interpretation for PA in the degree of different portions of reactor volume $\mathrm{dV}$. $F_{P A 0}$, feed flow rate, is maintained constant. On the other hand, $-r_{P A}$ is a function of the reactants concentration, catalyst concentration (if any) and the reaction temperature. Rearranging the expression of Eq. (14), as a result, resulting into Eq. (15) and Eq. (16)

$\tau=\frac{V}{v_{0}}=\frac{V C_{P A 0}}{F_{P A 0}}=C_{P A 0} \int_{0}^{X_{P A e}} \frac{d X_{P A}}{-r_{P A}}$

$\tau=\frac{V}{v_{0}}=\frac{V C_{P A 0}}{F_{P A 0}}=C_{S A} C_{P A 0} \int_{0}^{X_{P A e}} \frac{d X_{P A}}{-r_{P A}}$.

For equimolar concentration $C_{P A 0}=C_{H P 0}$ and $C_{P P A 0}=C_{W 0}=0$ at time $t=0$, at equilibrium (Eq. (17)) $-\frac{d C_{P A}}{d t}=0$.

Consequently, the equilibrium constant $\left(K_{e}\right)$ is determined by Eq. (18)

$K_{e}=\frac{k_{1}}{k_{2}}=\frac{C_{P P A e} C_{W e}}{C_{P A e} C_{H P e}}=\frac{X_{P A e}^{2}}{\left(1-X_{P A e}\right)^{2}}$. 
Table 2 Comparison of activation energy with literature and present study.

\begin{tabular}{|c|c|c|}
\hline \multicolumn{3}{|c|}{ Activation Energy $\left(E_{a}\right)$} \\
\hline $\begin{array}{l}\text { Homogeneous catalyst } \\
\text { (Sulfuric acid) }\end{array}$ & Heterogeneous catalyst & $\begin{array}{l}\text { Remarks / } \\
\text { Reference }\end{array}$ \\
\hline $60.4 \mathrm{~kJ} / \mathrm{mol} @ 46.4^{\circ} \mathrm{C}$ & - & {$[6]$} \\
\hline & $\begin{array}{c}43.20 \text { kJ/mol @ } 45^{\circ} \mathrm{C} \\
\text { (Amberlite IR-120) }\end{array}$ & [11] \\
\hline $44.24 \mathrm{~kJ} / \mathrm{mol} @ 45^{\circ} \mathrm{C}$ & $\begin{array}{c}51.4 \mathrm{~kJ} / \mathrm{mol} @ 45{ }^{\circ} \mathrm{C} \\
\text { (Amberlite IR-120) }\end{array}$ & {$[45]$} \\
\hline $\begin{array}{l}43.90 \mathrm{~kJ} / \mathrm{mol} \\
\text { (without catalyst) }\end{array}$ & & \\
\hline $\begin{array}{l}42.31 \mathrm{~kJ} / \mathrm{mol} \\
\text { (with catalyst) } \\
\text { Both @ } 45{ }^{\circ} \mathrm{C}\end{array}$ & - & Present study \\
\hline
\end{tabular}

From the Eq. (1), Eq. (3), Eq. (8) and Eq. (10) and after integration, attained Eq. (19) and Eq. (20)

$$
\begin{aligned}
& \ln \left[\frac{\left(X_{P A e}-\left(2 X_{P A e}-1\right) X_{P A}\right)}{\left(X_{P A e}-X_{P A}\right)}\right]=2 k_{1}\left(\frac{1}{X_{P A e}}-1\right) C_{P A 0} \tau \\
& \ln \left[\frac{\left(X_{P A e}-\left(2 X_{P A e}-1\right) X_{P A}\right)}{\left(X_{P A e}-X_{P A}\right)}\right]=2 k_{1}\left(\frac{1}{X_{P A e}}-1\right) C_{S A} C_{P A 0} \tau .
\end{aligned}
$$

From Eq. (19) and Eq. (20) [39-41] and Fig. 7 to Fig. 10 were used to find the activation energies and the reaction rate constants for the PPA synthesis and hydrolysis without and with catalyst.

From Fig. 8 and Fig. 10, the activation energies of PPA synthesis and hydrolysis were determined as 43.897 and $20.658 \mathrm{~kJ} / \mathrm{mol}$ without catalyst and 42.314 and $17.514 \mathrm{~kJ} / \mathrm{mol}$ with catalyst loading of $10 \mathrm{~mol} \%$ based on PA respectively. Comparison of Activation energy with literature and present study was shown in Table 2 . The activation energy of forward reaction is greater than the backward reaction. As a result, it could be noticed that the breakdown of PPA is predominant by the temperature considerably over the PPA synthesis and hydrolysis. The reaction rate constants $k_{1}$ and $k_{2}$ for PA without and with catalyst could be estimated from Eqs. (21)-(24)

$$
\begin{aligned}
& k_{1}=13.983 \times 10^{3} \exp \left(\frac{-43897.2345}{R T}\right), \quad \mathrm{L} /\left(\mathrm{mol}^{*} \min \right) \\
& k_{2}=1.87 \times 10^{2} \exp \left(\frac{-20658.2067}{\mathrm{RT}}\right), \quad \mathrm{L} /\left(\mathrm{mol}^{*} \mathrm{~min}\right) \\
& k_{1}=52.013 \times 10^{4} \exp \left(\frac{-42314.9849}{\mathrm{RT}}\right), \quad \mathrm{L}^{2} /\left(\mathrm{mol}^{2} * \min \right)
\end{aligned}
$$

$$
k_{2}=8.068 \exp \left(\frac{-17514.4943}{\mathrm{RT}}\right), \mathrm{L}^{2} /\left(\mathrm{mol}^{2} * \min \right) .
$$

\subsection{Hydrodynamics of fluid flow through helical capillary microreactor}

The experiments were performed at different temperatures and at different flow rates. The flow pattern behavior in the microreactor was laminar flow and it was confirmed by evaluating Reynolds number (Re). The Reynolds number was estimated by considering internal diameter and velocity at the inlet of the microreactor by Eq. (25)

$\operatorname{Re}=\frac{d v \rho}{\mu}$.

Where $\mu, \rho, v$ and $d$ are viscosity of the solution mixture, density of the fluid, velocity and internal diameter of the microreactor respectively. Here the density of the solution was treated as the fluid density $\left(998 \mathrm{~kg} / \mathrm{m}^{3}\right)$ and the viscosity of solution (2.752 $\mathrm{m} \mathrm{Pa}$. s) was determined by Rheometer (Model No. QC SN80156956 - FW1.20). The determined $\mathrm{Re}$ is in the range of $0.802-11.542$. Hence, the flow pattern is laminar flow in the microreactor.

The Dean number (De) is a dimensionless and provides information of flow in helical capillaries. As stated by the $\mathrm{Re}$, it can interpret a physical interpretation of De, it is defined by Eq. (26)

$$
\begin{aligned}
\text { De } & =\frac{\sqrt{(\text { Centripetal forces }) *(\text { Inertial forces })}}{\text { Viscous forces }} \\
& =\frac{\rho v d}{\mu} * \sqrt{\frac{d_{t}}{r_{c}}}=\operatorname{Re} * \sqrt{\frac{d_{t}}{r_{c}}} .
\end{aligned}
$$

Where $d_{t}$ is the tube inlet diameter and $r_{c}$ is the radius of curvature of the microreactor. For the experiments, De in the range of $0.197-2.836$ for $r_{c}=13.25 \mathrm{~mm}$ and $0.149-2.141$ for $r_{c}=23.25 \mathrm{~mm}$.

The dimensional analysis described that the fully developed laminar flow of a fluid in a coiled tube can be described by a dimensionless group which is the product $f^{*}$ Re. In case of the flow in helical tubes, the pressure drop is higher when compared to straight tube at the same operating conditions.

In experiment, helical capillary microreactor was used as mentioned above. The curved tube friction factor, $f_{c}$, for helical capillary microreactor was calculated. The $f_{c}$ for fully developed laminar flow is given by Eq. (27)

$f_{c}=f_{s}\left(1.03058 *\left(\frac{\mathrm{De}^{2}}{288}\right)^{2}+0.01195 *\left(\frac{\mathrm{De}^{2}}{288}\right)^{4}\right)$.

Where De is Dean Number, $f_{s}$ is straight tube friction factor. Using the Eq. (26), the $f_{c}$ for helical capillary microreactor is calculated by using De and $f_{s}(=16 / \mathrm{Re})$. The determined $f_{c}$ is in the range of $3.73 * 10^{-7}-1.11 * 10^{-3}$ for $r_{c}=13.25 \mathrm{~mm}$ and $1.21 * 10^{-7}-3.62 * 10^{-4}$ for $r_{c}=23.25 \mathrm{~mm}$. Therefore, it could be concluded that as 
Table 3 Comparison of flow rate, Reynolds number, Dean Number, curve friction factor and pressure drop for different radius of curvatures.

\begin{tabular}{llcccccc}
\hline $\begin{array}{l}Q \\
\mathrm{~mL} / \mathrm{h}\end{array}$ & $\mathrm{Re}$ & $\mathrm{M}$ & $f_{c}=13.25 \mathrm{~mm}$ & $\begin{array}{l}\Delta p / L, \\
\mathrm{~Pa} / \mathrm{m}\end{array}$ & $\mathrm{De}$ & $f_{c}$ & $\begin{array}{c}\Delta p / L, \\
\mathrm{~Pa} / \mathrm{m}\end{array}$ \\
\hline 5.0 & 0.802 & 0.197 & $3.73 \mathrm{E}-7$ & 78.368 & 0.149 & $1.21 \mathrm{E}-07$ & 70.827 \\
6.0 & 0.962 & 0.236 & $6.45 \mathrm{E}-7$ & 100.421 & 0.178 & $2.09 \mathrm{E}-07$ & 90.758 \\
7.5 & 1.202 & 0.295 & $1.26 \mathrm{E}-6$ & 136.027 & 0.223 & $4.09 \mathrm{E}-07$ & 122.937 \\
10.0 & 1.603 & 0.394 & $2.98 \mathrm{E}-6$ & 201.159 & 0.297 & $9.70 \mathrm{E}-07$ & 181.802 \\
15.0 & 2.405 & 0.591 & $1.01 \mathrm{E}-5$ & 349.160 & 0.446 & $3.27 \mathrm{E}-06$ & 315.560 \\
30.0 & 4.809 & 1.182 & $8.06 \mathrm{E}-5$ & 896.242 & 0.892 & $2.62 \mathrm{E}-05$ & 809.997 \\
72.0 & 11.542 & 2.836 & $1.11 \mathrm{E}-3$ & 2947.900 & 2.141 & $3.62 \mathrm{E}-04$ & 2664.223 \\
\hline
\end{tabular}

the residence time increases, the De decreases because of the decrease in the velocity, which leads to decrease in $f_{c}$. It was noticed that, their effects were high in $r_{c}=13.25 \mathrm{~mm}$ when compared to $r_{c}=23.25 \mathrm{~mm}$.

The pressure drop is an important parameter in the design of a helical capillary microreactor [42]. In the experiments, horizontal helical capillary microreactor with homogeneous liquid flow in the laminar regime was considered. The pressure drop $(\Delta P)$ is owing to frictional effects of the fluid flow, for laminar flow, is reported by the Hagen-Poiseuille equation (Eq. (28))

$\frac{\Delta P}{L}=\frac{32 \mu v}{d_{t}^{2}}$.

Where $L$ is the length of the capillary, $\mu$ viscosity of the fluid, $v$ is the velocity of fluid flowing in the helical capillary microreactor, $d_{t}$ is the capillary internal diameter.

White [43] has reported that the pressure drop in a helical tube is a function of the De, defined by Eq. (29):

$$
f(\mathrm{De})=0.37 \mathrm{De}^{0.36} \text {. }
$$

Consequently, the resistance of laminar flow in a straight tube (Eq. (28)) could be multiplied with Eq. (29) and yields the Eq. (30) [44]

$\frac{\Delta P}{L}=\frac{32 \mu v}{d_{t}^{2}} * 0.37 \mathrm{De}^{0.36}$.

By Eq. (30), the pressure drop was determined for the helical capillary microreactor in the range

\section{References}

[1] Prescher, G., Weiberg, O., Waldmann, H., Seifert, H., Deutsche Gold- und Silber-Scheideanstalt vormals Roessler, Bayer Aktiengesellschaft "Process for the preparation of perpropionic acid solutions", Germany, US4088679A, 1978.

[2] Inaba, Y., Hirakawa, T., Ueno, Y., Takiguchi, S., Ube Industries Ltd. "Process for preparing perpropionic acid solution", Japan, US5206425A, 1993. of $78.368-2947.900 \mathrm{~Pa} / \mathrm{m}$ for $r_{c}=13.25 \mathrm{~mm}$ and $70.827-2664.223 \mathrm{~Pa} / \mathrm{m}$ for $r_{c}=23.25 \mathrm{~mm}$. The comparison of flow rate $(Q), \mathrm{Re}, \mathrm{De}, f_{c}$ and pressure drop of $r_{c}=13.25 \mathrm{~mm}$ and $r_{c}=23.25 \mathrm{~mm}$ respectively are given in Table 3. The pressure drop calculation is helpful for the determination of the power consumption.

\section{Conclusion}

The synthesis of PPA in THCMR was efficiently performed without and with a homogeneous catalyst such as sulfuric acid. The best reaction conditions for the synthesis of PPA were total feed flow rate of $6 \mathrm{~mL} / \mathrm{h}$ (residence time of $10 \mathrm{~min}$ ), molar ratio of $\mathrm{HP}$ to $\mathrm{PA}$ is $1: 1$, temperature of $50{ }^{\circ} \mathrm{C}$ and $10 \mathrm{~mol} \%$ catalyst concentration based PA. Hence, the maximum conversion of the PA at these parameter was $X_{P A}=72.36 \%$. Furthermore, the reaction time was considerably decreased and reaction rate was significantly increased in the presence of catalyst in THCMR with a radius of curvature of $13.25 \mathrm{~mm}$. Hence, reaction gets completed within $10 \mathrm{~min}$ in THCMR as compared to conventional batch processes. The reaction rate constants expressions were determined. The continuous flow microreactor for the synthesis of peroxypropionic acid was efficiently demonstrated and the technology might be advantageous technique for similar percarboxylic acid synthesis. The hydrodynamic study of the helical capillary microreactor explained briefly.

[3] Xiaobing, Z., Xinji, Z., Jianjun, Z., Zhiquan, X., Yuanyuan, Y., Xinji, Z. "Method for preparing peroxy acetic acid", China, CN1803771A, 2006.

[4] Aksela, R., Renvall, I., Oyj, K., Aksela, R., Renvall, I. "Process for the preparation of peroxy acids", French, WO 2007/031596 A3, 2007.

[5] Kitis, M. "Disinfection of wastewater with peracetic acid: a review", Environment International, 30(1), pp. 47-55, 2004. https://doi.org/10.1016/S0160-4120(03)00147-8 
[6] Leveneur, S., Salmi, T., Murzin, D. Y., Estel, L., Wärnå, J., Musakka, N. "Kinetic Study and Modeling of Peroxypropionic Acid Synthesis from Propionic Acid and Hydrogen Peroxide Using Homogeneous Catalysts", Industrial \& Engineering Chemistry Research, 47(3), pp. 656-664, 2008. https://doi.org/10.1021/ie070670e

[7] Luukkonen, T., Pehkonen, S. O. "Peracids in water treatment: A critical review", Critical Reviews in Environmental Science and Technology, 47(1), pp. 1-39, 2017. https://doi.org/10.1080/10643389.2016.1272343

[8] Leveneur, S., Murzin, D. Y., Salmi, T., Mikkola, J.-P., Kumar, N., Eränen, K., Estel, L. "Synthesis of peroxypropionic acid from propionic acid and hydrogen peroxide over heterogeneous catalysts", Chemical Engineering Journal, 147(2-3), pp. 323-329, 2009. https://doi.org/10.1016/j.cej.2008.11.045

[9] De Filippis, P., Scarsella, M., Verdone, N. "Peroxyformic Acid Formation: A Kinetic Study", Industrial \& Engineering Chemistry Research, 48(3), pp. 1372-1375, 2009. https://oi.org/10.1021/ie801163j

[10] Maralla, Y., Sonawane, S. "Process intensification using a spiral capillary microreactor for continuous flow synthesis of performic acid and it's kinetic study", Chemical Engineering and Processing Process Intensification, 125, pp. 67-73, 2018. https://doi.org/10.1016/j.cep.2018.01.009

[11] Leveneur, S., Wärnå, J., Eränen, K., Salmi, T. "Green process technology for peroxycarboxylic acids: Estimation of kinetic and dispersion parameters aided by RTD measurements: Green synthesis of peroxycarboxylic acids", Chemical Engineering Science, 66(6), pp. 1038-1050, 2011.

https://doi.org/10.1016/j.ces.2010.12.005

[12] Dessimoz, A.-L., Cavin, L., Renken, A., Kiwi-Minsker, L. "Liquid-liquid two-phase flow patterns and mass transfer characteristics in rectangular glass microreactors", Chemical Engineering Science, 63(16), pp. 4035-4044, 2008.

https://doi.org/10.1016/j.ces.2008.05.005

[13] Némethné-Sóvágó, J., Benke, M. "Microreactors: A New Concept for Chemical Synthesis and Technological Feasibility (Review)", Materials Science and Engineering, 39(2), pp. 89-101, 2014. [online] Available at: http://www.mak.uni-miskolc.hu/wp-content/uploads/2018/02/MATERIALS-SCIENCE-2014-2.pdf [Accessed: 02 February 2017]

[14] Makarshin, L. L., Pai, Z. P., Parmon, V. N. "Microchannel systems for fine organic synthesis", Russian Chemical Reviews, 85(2), pp. 139-155, 2016. https://doi.org/10.1070/RCR4484

[15] Löb, P., Löwe, H., Hessel, V. "Fluorinations, chlorinations and brominations of organic compounds in micro reactors", Journal of Fluorine Chemistry, 125(11), pp. 1677-1694, 2004.

https://doi.org/10.1016/j.jfluchem.2004.09.006

[16] Löbbecke, S., Antes, J., Ferstl, W., Boskovic, D., Türcke, T., Schwarzer, M., Krause, H. "Microreactors for processing of hazardous and explosible reactions", Institution of Chemical Engineers Symposium Series, 153, pp. 1-6, 2007. [online] Available at: http://www.icheme.org/communities/special-interest-groups/safety $\% 20$ and $\% 201$ oss $\% 20$ prevention/resources/hazards\%20archive/lp2007.aspx [Accessed: 04 July 2016]
[17] Singh, J., Kockmann, N., Nigam, K. D. P. "Novel three-dimensional microfluidic device for process intensification", Chemical Engineering and Processing: Process Intensification, 86, pp. 78-89, 2014.

https://doi.org/10.1016/j.cep.2014.10.013

[18] Kockmann, N., Roberge, D. M. "Transitional Flow and Related Transport Phenomena in Curved Microchannels", Heat Transfer Engineering, 32(7-8), pp. 595-608, 2011. https://doi.org/10.1080/01457632.2010.509753

[19] Fischer, M., Kockmann, N. "Enhanced Convective Mixing and Residence Time Distribution in Advanced Micromixers", In: $10^{\text {th }}$ International Conference on Nanochannels, Microchannels, and Minichannels, Rio Grande, Puerto Rico, USA, 2012, pp. 481-488. https://doi.org/10.1115/ICNMM2012-73275

[20] Thakur, R. K., Vial, C., Nigam, K. D. P., Nauman, E. B., Djelveh, G. "Static Mixers in the Process Industries - A Review", Chemical Engineering Research and Design, 81(7), pp. 787-826, 2003. https://doi.org/10.1205/026387603322302968

[21] Greenspan, F. P., MacKellar, D. G. "Analysis of Aliphatic Per Acids", Analytical Chemistry, 20(11), pp. 1061-1063, 1948. https://doi.org/10.1021/ac60023a020

[22] Swern, D. "Organic Peroxides", 1st ed., Wiley-Interscience, New York, USA, Vol. 1, 1970.

[23] Leveneur, S., Thönes, M., Hébert, J.-P., Taouk, B., Salmi, T. "From Kinetic Study to Thermal Safety Assessment: Application to Peroxyformic Acid Synthesis", Industrial \& Engineering Chemistry Research, 51(43), pp. 13999-14007, 2012. https://doi.org/10.1021/ie3017847

[24] Gaikwad, S. M., Jolhe, P. D., Bhanvase, B. A., Kulkarni, A., Patil, V. S., Pimplapure, M. S., Suranani, S., Potoroko, I., Sonawane, S. H., Sonawane, S. S. "Process intensification for continuous synthesis of performic acid using Corning advanced-flow reactors", Green Processing and Synthesis, 6(2), pp. 189-196, 2017. https://doi.org/10.1515/gps-2016-0147

[25] Jolhe, P. D., Bhanvase, B. A., Patil, V. S., Sonawane, S. H. "Sonochemical synthesis of peracetic acid in a continuous flow micro-structured reactor", Chemical Engineering Journal, 276, pp. 91-96, 2015. https://doi.org/10.1016/j.cej.2015.04.054

[26] Jolhe, P. D., Bhanvase, B. A., Patil, V. S., Sonawane, S. H., Potoroko, I. "Ultrasound assisted synthesis of performic acid in a continuous flow microstructured reactor", Ultrasonics Sonochemistry, 39, pp. 153-159, 2017. https://doi.org/10.1016/j.ultsonch.2017.03.059

[27] Ehrfeld, W., Hessel, V., Löwe, H. "Microreactors: New Technology for Modern Chemistry", 1st ed., Wiley-VCH, Weinheim, Germany, 2000.

[28] Prabhanjan, D. G., Raghavan, G. S. V., Rennie, T. J. "Comparison of heat transfer rates between a straight tube heat exchanger and a helically coiled heat exchanger", International Communication in Heat and Mass Transfer, 29(2), pp. 185-191, 2002. https://doi.org/10.1016/S0735-1933(02)00309-3

[29] Dummann, G., Quittmann, U., Gröschel, L., Agar, D. W., Wörz, O., Morgenschweis, K. "The capillary-microreactor: a new reactor concept for the intensification of heat and mass transfer in liquidliquid reactions", Catalysis Today, 79-80, pp. 433-439, 2003. https://doi.org/10.1016/S0920-5861(03)00056-7 
[30] Engler, M., Kockmann, N., Kiefer, T., Woias, P. "Convective Mixing and Its Application to Micro Reactors", In: $2^{\text {nd }}$ International Conference on Microchannels and Minichannels, Rochester, New York, USA, 2004, pp. 781-788.

https://doi.org/10.1115/ICMM2004-2412

[31] Chingulpitak, S., Wongwises, S. "A comparison of flow characteristics of refrigerants flowing through adiabatic straight and helical capillary tubes", International Communications in Heat and Mass Transfer, 38(3), pp. 398-404, 2011.

https://doi.org/10.1016/j.icheatmasstransfer.2010.12.014

[32] Kurt, S. K., Gelhausen, M. G., Kockmann, N. "Axial Dispersion and Heat Transfer in a Milli/Microstructured Coiled Flow Inverter for Narrow Residence Time Distribution at Laminar Flow", Chemical Engineering \& Technology, 38(7), pp. 1122-1130, 2015. https://doi.org/10.1002/ceat.201400515

[33] Khairul, M. A., Saidur, R., Rahman, M. M, Alim, M. A, Hossain, A., Abdin, Z. "Heat transfer and thermodynamic analyses of a helically coiled heat exchanger using different types of nanofluids", International Journal of Heat and Mass Transfer, 67, pp. 398-403, 2013.

https://doi.org/10.1016/j.ijheatmasstransfer.2013.08.030

[34] Maralla, Y., Sonawane, S., Kashinath, D., Pimplapure, M., Paplal, B. "Process Intensification of Tetrazole reaction through tritylation of 5-[4'- (Methyl) Biphenyl-2-Yl] using microreactors", Chemical Engineering and Processing: Process Intensification, 112, pp. 9-17, 2017.

https://doi.org/10.1016/j.cep.2016.12.003

[35] Mošovský, V., Cvengrošová, Z., Kaszonyi, A., Králik, M., Hronec, M. "Kinetics of Formation of Peroxyformic Acid", Collection of Czechoslovak Chemical Communications, 61(10), pp. 1457-1463, 1996. https://doi.org/10.1135/cccc19961457

[36] Dean, J. A. "Lange's Handbook of Chemistry", 15th ed., McGrawHill, Inc., New York, USA, 1999. [online] Available at: http://fptl.ru/ biblioteka/spravo4niki/dean.pdf [Accessed: 17 September 2017]
[37] Santacesaria, E., Russo, V., Tesser, R., Turco, R., Di Serio, M. "Kinetics of Performic Acid Synthesis and Decomposition", Industrial \& Engineering Chemistry Research, 56(45), pp. 12940-12952, 2017.

https://doi.org/10.1021/acs.iecr.7b00593

[38] Ebrahimi, F., Kolehmainen, E., Oinas, P., Hietapelto, V., Turunen, I. "Production of unstable percarboxylic acids in a microstructured reactor", Chemical Engineering Journal, 167(2-3), pp. 713-717, 2011.

https://doi.org/10.1016/j.cej.2010.08.091

[39] Levenspiel, O. "Chemical Reaction Engineering", 3rd ed., John Wiley \& Sons, Inc., New York, United States of America, 1998.

[40] Missen, R. W., Mims, C. A., Saville, B. A. "Introduction to Chemical Reaction Engineering and Kinetics", 1st ed., John Wiley \& Sons, Inc., New York, United States of America, 1999.

[41] Fogler, H. S. "Elements of Chemical Reaction Engineering", 4th ed., Pearson Education Inc., Upper Saddle River, New Jersey, USA, 2006.

[42] Naphon, P., Wongwises, S. "A review of flow and heat transfer characteristics in curved tubes", Renewable and Sustainable Energy Reviews, 10(5), pp. 463-490, 2006. https://doi.org/10.1016/j.rser.2004.09.014

[43] White, C. M. "Streamline Flow through Curved Pipes", Proceedings of the Royal Society of London, Series A, Containing Papers of a Mathematical and Physical Character, 123(792), pp. 645-663, 1929. https://doi.org/10.1098/rspa.1929.0089

[44] Garber, A., Hernandez, L., Mullin, C., Simon, M. "Pressure Flow Through a Coiled Tube", Group M5, BE 310 Spring 2004. [online] Available at: https://www.seas.upenn.edu/ belab/ LabProjects/2004/be310s04m5.doc [Accessed: 03 November 2016]

[45] Leveneur, S., Wärnå, J., Salmi, T., Murzin, D. Y., Estel, L. "Interaction of intrinsic kinetics and internal mass transfer in porous ion-exchange catalysts: Green synthesis of peroxycarboxylic acids", Chemical Engineering Science, 64(19), pp. 4101-4114, 2009. https://doi.org/10.1016/j.ces.2009.05.055 